BMJ Open Diabetes

Research \& Care

\section{Eligibility of patients with type 2 diabetes for sodium-glucose cotransporter 2 inhibitor cardiovascular outcomes trials: a global perspective from the DISCOVER study}

To cite: Pintat S, Fenici $P$, Hammar N, et al. Eligibility of patients with type 2 diabetes for sodium-glucose cotransporter 2 inhibitor cardiovascular outcomes trials: a global perspective from the DISCOVER study. BMJ Open Diab Res Care 2019;7:e000627. doi:10.1136/ bmjdrc-2018-000627

- Additional material is published online only. To view please visit the journal online (http://dx.doi.org/10.1136/ bmjdrc-2018-000627).

Received 22 October 2018 Revised 8 January 2019 Accepted 16 January 2019

Check for updates

C Author(s) (or their employer(s)) 2019. Re-use permitted under CC BY-NC. No commercial re-use. See rights and permissions. Published by BMJ.

For numbered affiliations see end of article.

Correspondence to Dr Kamlesh Khunti; kk22@leicester.ac.uk

\section{ABSTRACT}

Objective To assess the eligibility of patients participating in DISCOVER (a 3-year, prospective, observational study program of 15992 patients with type 2 diabetes [T2D] initiating a second-line glucose-lowering therapy across 38 countries) for four cardiovascular outcomes trials (CVOTs) of sodium-glucose cotransporter 2 inhibitors (CANagliflozin cardioVascular Assessment Study [CANVAS], Dapagliflozin effect on CardiovascuLAR Events trial [DECLARE-TIMI 58], EMPAgliflozin cardiovascular OUTCOME event trial [EMPA-REG OUTCOME], and eValuation of ERTugliflozin efflcacy and Safety CardioVascular outcomes trial [VERTIS-CV]).

Research design and methods In this cross-sectional analysis, baseline characteristics of DISCOVER patients were compared with the inclusion and exclusion criteria of the CVOTs to assess patient eligibility, overall and in four regions (Asia-Pacific, Europe, Latin America, and Middle East and Africa).

Results Overall, 11385 patients (71.2\%) had sufficient data for the analysis; $56.1 \%$ were men. The mean age and time since T2D diagnosis were 57.4 and 5.6 years, respectively. The mean glycated hemoglobin level was $8.3 \%$. DISCOVER patients were younger, and fewer had a history of cardiovascular disease, than those enrolled in the CVOTs. Eligibility varied across the CVOTs; the proportion of eligible DISCOVER patients was highest for DECLARE-TIMI 58 (40.5\%), followed by CANVAS (19.9\%), VERTIS-CV (7.2\%), and EMPAREG OUTCOME (7.1\%); $54.6 \%$ of patients were not eligible for any CVOT. Eligibility for each CVOT varied across regions, which was explained by the differing proportions of patients with established cardiovascular disease.

Conclusions In a large, international population of patients with T2D initiating a second-line glucose-lowering therapy, DECLARE-TIMI 58 was the most inclusive CVOT, suggesting that its study population will be more representative of patients encountered in routine clinical practice than those of CANVAS, EMPA-REG OUTCOME, and VERTIS-CV.

\section{INTRODUCTION}

Type 2 diabetes (T2D) is associated with an increased risk of both microvascular and macrovascular complications. ${ }^{1}{ }^{2}$ Sustained glycemic control has been shown to reduce

\section{Significance of this study}

What is already known about this subject?

- Cardiovascular outcomes trials (CVOTs) of sodiumglucose cotransporter 2 (SGLT-2) inhibitors, such as the CANagliflozin cardioVascular Assessment Study (CANVAS) and the EMPAgliflozin cardiovascular OUTCOME event trial (EMPA-REG OUTCOME), have shown a reduction of cardiovascular events in patients with type 2 diabetes (T2D) using SGLT-2 inhibitors.

- However, analyses using US and UK databases have shown that eligibility of patients with T2D varied greatly across four completed or ongoing SGLT-2 inhibitor CVOTs (CANVAS, Dapagliflozin effect on CardiovascuLAR Events trial [DECLARETIMI 58], EMPA-REG OUTCOME, and eValuation of ERTugliflozin efflcacy and Safety CardioVascular outcomes trial [VERTIS-CV]), suggesting that the generalizability of their results may also vary.

What are the new findings?

- The eligibility of patients enrolled in DISCOVER (a large observational study of patients with T2D initiating a second-line glucose-lowering therapy across 38 countries) varied across the four CVOTs.

- DECLARE-TIMI 58 was the most inclusive CVOT ( $40.5 \%$ of DISCOVER patients were eligible), followed by CANVAS (19.9\%), VERTIS-CV (7.2\%), and EMPA-REG OUTCOME (7.1\%); $54.6 \%$ of DISCOVER patients were not eligible for any of the four CVOTs.

the risk of microvascular complications. ${ }^{3-7}$ However, contradictory results have been published about its effects on the risk of cardiovascular disease (CVD), ${ }^{89}$ and some studies suggest that intensive glycemic control and some glucose-lowering therapies may be associated with an increased risk of cardiovascular (CV) events and death. ${ }^{10-13}$ 


\section{Significance of this study}

How might these results change the focus of research or clinical practice?

- Findings from CVOTs are not equally generalizable and should be interpreted considering their inclusion and exclusion criteria to ensure that they apply to patients managed in routine clinical settings.

- Further efforts are needed to include a more diverse sample of patients in CVOTs, including those with lower cardiovascular risk and those from rarely studied regions such as the Middle East and Africa.

As a result, the US Food and Drug Administration (FDA) issued guidance on conducting cardiovascular outcomes trials (CVOTs) to assess the CV safety of new glucose-lowering agents. ${ }^{14}$ In line with the FDA recommendations, randomized controlled CVOTs have been conducted or are ongoing to determine the $\mathrm{CV}$ safety profile of sodium-glucose cotransporter 2 (SGLT-2) inhibitors. ${ }^{15-20}$ The EMPAgliflozin cardiovascular OUTCOME event trial (EMPA-REG OUTCOME; NCT01131676) and CANagliflozin cardioVascular Assessment Study Program (CANVAS Program; NCT01032629 and NCT01989754) have been completed, and showed a reduction in the risk of CV events in patients using SGLT-2 inhibitors. For example, in the EMPA-REG OUTCOME trial, use of empagliflozin was associated with a significantly decreased occurrence of the primary composite outcome (CV death, non-fatal myocardial infarction, or non-fatal stroke) compared with placebo in patients with established CVD (HR: 0.86, $\mathrm{p}=0.04$ for superiority). ${ }^{21}$ Similarly, results from CANVAS showed that canagliflozin reduced the occurrence of the same composite endpoint compared with placebo in patients with established CVD and those at high risk of CV events (HR: 0.86, $p=0.02$ for superiority).$^{22}$ Both trials also showed a statistically significant reduction in the risk of hospitalization for heart failure (HR vs placebo: 0.65 [95\% CI 0.50 to 0.85 ] for empagliflozin and 0.67 [95\% CI 0.52 to 0.87 ] for canagliflozin). Although data from the Dapagliflozin effect on CardiovascuLAR Events trial (DECLARE-TIMI 58; NCT01730534) were not available at the time of this analysis, top-line results communicated by the study sponsor showed that dapagliflozin was non-inferior to placebo for major adverse CV events, and significantly reduced the combined risk of hospitalization for heart failure and $\mathrm{CV}$ death. ${ }^{23}$ The eValuation of ERTugliflozin effIcacy and Safety CardioVascular outcomes trial (VERTIS-CV trial; NCT01986881) was ongoing at the time of writing and no data were available.

Understanding the similarities and differences between each CVOT population and patients with T2D encountered in routine clinical practice, as well as the generalizability of results from CVOTs, is crucial to help physicians to assess the applicability of the trial findings to their patients. The broader the inclusion criteria of the CVOT, the more likely the study participants are to be representative of patients treated in routine clinical practice. A recent cross-sectional retrospective study based on 20293 patients included in the National Health and Nutrition Examination Survey (NHANES) has shown that the estimated proportion of US patients with T2D who would have been eligible for each of the four SGLT-2 inhibitor CVOTs varied greatly, from $4.1 \%$ to $39.8 \% .{ }^{24}$ In another analysis of 182525 patients with T2D participating in the US Diabetes Collaborative Registry (DCR), only $26.2 \%$ met the main eligibility criteria for the EMPA-REG OUTCOME trial. ${ }^{25}$ Notably, the DCR population included a high proportion of patients with established CVD. Similarly, a UK database study showed that only $15.7 \%$ of 60327 patients from 128 general practitioner practices had the same high $\mathrm{CV}$ risk as those included in the EMPA-REG OUTCOME trial. ${ }^{26}$

However, these assessments used US and UK data sets, and it is crucial to be able to compare CVOTs and to assess their generalizability in other regions of the world. DISCOVER is a large, international, 3-year, prospective, observational study of the treatment and outcomes of patients with T2D initiating a second-line glucose-lowering therapy. The study includes 38 countries across six continents; an estimated $70 \%$ of patients with diabetes lived in these countries in 2017. ${ }^{27}$ Approximately 16000 patients were recruited at the time of changing from firstline to second-line glucose-lowering therapy. This population is of particular interest because relatively young patients who are early in the disease process have rarely been studied. The aim of DISCOVER is to assess treatment patterns and associated outcomes. ${ }^{28}$ In many of the included countries, DISCOVER participants constitute the only well-characterized population of patients with T2D.

The objective of the present analysis is to estimate the eligibility of DISCOVER patients at study baseline (initiation of second-line glucose-lowering therapy) for inclusion in CANVAS, DECLARE-TIMI 58, EMPA-REG OUTCOME, and VERTIS-CV, globally and in different regions of the world.

\section{RESEARCH DESIGN AND METHODS \\ The DISCOVER study program}

The DISCOVER study program comprises two similar, 3-year, observational, prospective studies conducted simultaneously in 38 countries: DISCOVER (NCT02322762) in 37 countries (Algeria, Argentina, Australia, Austria, Bahrain, Brazil, Canada, China, Colombia, Costa Rica, Czech Republic, Denmark, Egypt, France, India, Indonesia, Italy, Jordan, Kuwait, Lebanon, Malaysia, Mexico, The Netherlands, Norway, Oman, Panama, Poland, Russia, Saudi Arabia, South Africa, South Korea, Spain, Sweden, Taiwan, Tunisia, Turkey, and the United Arab Emirates) and J-DISCOVER (NCT02226822) in Japan.

The methods of the DISCOVER study program have been described in detail elsewhere ${ }^{28}$ and are summarized below. 
Sites and investigators selection, and patient recruitment

Management of T2D was assessed in each participating country before the start of the study, using information from peer-reviewed articles, reports published by international healthcare organizations and insights from national experts, who acted as national coordinating investigators in each country. A diverse sample of sites (primary care centers or hospitals located in both rural and urban areas, and funded publicly or privately) and investigators (primary care physicians or specialists such as diabetologists and endocrinologists) that would match the results from the initial assessment as much as possible were invited to participate. ${ }^{28} 29$ The study protocol stated that participating physicians should invite consecutive eligible patients (online supplementary table 1) to take part in the study. All participating patients provided signed informed consent.

\section{Data collection}

A standardized electronic case report form was used to collect DISCOVER data at baseline (initiation of secondline therapy); in Canada, Denmark, France, Norway, and Sweden, data were partially extracted from existing medical records or health registries and an abbreviated electronic case report form was used. Relevant information for the assessment of the eligibility of DISCOVER patients for CVOTs included patient characteristics (age, body mass index [BMI] and time since T2D diagnosis); clinical variables (glycated hemoglobin $\left[\mathrm{HbA}_{1 \mathrm{c}}\right]$ level, estimated glomerular filtration rate [eGFR], low-density lipoprotein cholesterol [LDL-C] level, high-density lipoprotein cholesterol [HDL-C] level, systolic blood pressure, and diastolic blood pressure); comorbidities (hypertension, hyperlipidemia, and chronic kidney disease $[\mathrm{CKD}])$; history of macrovascular complications (coronary artery disease [coronary artery disease, angina, myocardial infarction, percutaneous coronary intervention, and coronary artery bypass grafting], cerebrovascular disease [stroke, transient ischemic attack, carotid artery stenting, and carotid endarterectomy], peripheral artery disease [history of peripheral artery disease including revascularization procedures, diabetic foot, and amputation], heart failure, and implantable cardioverter defibrillator use); smoking status; and use of comedications (lipid-lowering drugs and antihypertensive drugs).

In line with the observational nature of the DISCOVER study, clinical variables were collected in accordance with routine clinical practice at each site; data collection was not mandatory for any of the variables. Similarly, the assessment of comorbidities relied on the investigators' judgment and was not adjudicated. To ensure data quality and to identify any issues with data collection, records for at least $10 \%$ of participants at each site were randomly selected during monitoring visits, and data entered in the electronic case report form were compared with the source data (eg, original laboratory analysis reports).

\section{Assessment of eligibility for CVOTs}

Inclusion and exclusion criteria for CANVAS, DECLARETIMI 58, EMPA-REG OUTCOME, and VERTIS-CV have been described elsewhere ${ }^{15}$; ; the main inclusion and exclusion criteria used for comparison with the DISCOVER population in this analysis are summarized in online supplementary table 2 , for patients with established CVD and patients with CV risk factors (but no established CVD), when applicable.

The DISCOVER variables and criteria used to assess eligibility for each CVOT are shown in table 1 . Not all variables required to assess eligibility for the CVOTs were collected in all DISCOVER patients. Therefore, only patients with data available for all the necessary variables to assess eligibility for all four CVOTs were included in the analysis: age, sex, $\mathrm{HbA}_{1 \mathrm{c}}$ level, $\mathrm{BMI}$, time since diagnosis of T2D, information on comorbidities (CVD, CKD, hypertension, and hyperlipidemia), and information on the use of comedications (lipid-lowering drugs and antihypertensive drugs). Patients with missing data for eGFR, LDL-C level, HDL-C level, systolic blood pressure, or diastolic blood pressure were not excluded because physicians could record the presence of CKD, hyperlipidemia, and hypertension in sections dedicated to comorbidities in the electronic case report form.

Descriptive data are reported for DISCOVER patients with sufficient data, overall and for patients in the following predefined regions: Asia-Pacific (Australia, China, India, Indonesia, Japan, Malaysia, South Korea, and Taiwan); Latin America (Argentina, Brazil, Colombia, Costa Rica, Mexico, and Panama); Europe (Austria, Czech Republic, Denmark, France, Italy, The Netherlands, Norway, Poland, Russia, Spain, and Sweden); and the Middle East and Africa (Algeria, Bahrain, Egypt, Jordan, Kuwait, Lebanon, Oman, Saudi Arabia, South Africa, Tunisia, Turkey, and the United Arab Emirates). A sensitivity analysis was also conducted to compare the eligibility of patients in countries in which data were partially extracted from existing medical records or health registries with that of patients in all other countries, in which data were exclusively collected with the electronic case report form.

\section{RESULTS}

Of the 15992 patients in the DISCOVER study, 11385 $(71.2 \%)$ had sufficient data to be included in the analysis; this proportion was similar across all studied regions (69.2\%-74.3\%; table 2$)$. The main reason for excluding patients from the analysis was missing $\mathrm{HbA}_{1 \mathrm{c}}$ data (not reported in $20.1 \%$ of patients).

\section{Baseline characteristics of DISCOVER patients included in the} analysis

Patients included in the analysis were from different ethnic origins (table 3); most patients were Asian (48.1\%), Caucasian (27.5\%), or Arabic (15.8\%). Their mean age was 57.4 years and there were more men than 
Table 1 Variables and criteria used to assess eligibility of patients in the DISCOVER study for inclusion in CANVAS, DECLARE-TIMI 58, EMPA-REG OUTCOME, and VERTIS-CV

\begin{tabular}{|c|c|c|c|c|}
\hline Criterion & CANVAS & DECLARE-TIMI 58 & EMPA-REG OUTCOME & VERTIS-CV \\
\hline \multicolumn{5}{|l|}{ All patients } \\
\hline $\mathrm{HbA}_{1 \mathrm{c},} \%$ & $7.0-10.5$ & $6.5-12.0$ & $7.0-10.0$ & $7.0-10.5$ \\
\hline CKD history & $\begin{array}{l}\text { Patients were excluded } \\
\text { if: } \\
\begin{array}{l}\text { eGFR was reported } \\
\text { and }<30 \mathrm{~mL} / \mathrm{min} / 1.73 \\
\mathrm{~m}^{2} . \\
\text { Or if CKD was } \\
\text { marked as present } \\
\text { by the investigator. }\end{array}\end{array}$ & $\begin{array}{l}\text { Patients were excluded if: } \\
\text { eGFR was reported and } \\
<60 \mathrm{~mL} / \mathrm{min} / 1.73 \mathrm{~m}^{2} \text {. } \\
\text { Or if CKD was marked } \\
\text { as present by the } \\
\text { investigator. }\end{array}$ & 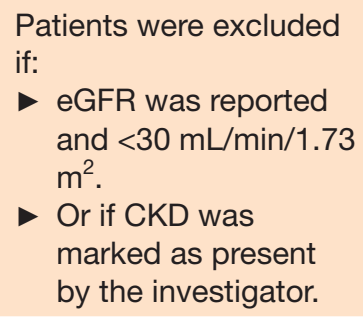 & No exclusion criterion \\
\hline $\mathrm{BMI}, \mathrm{kg} / \mathrm{m}^{2}$ & No criterion & & & $\geq 18.0$ \\
\hline \multicolumn{5}{|c|}{ Patients with CV risk factors but no established CVD } \\
\hline Age, years & $\geq 50$ & >55 (men), >60 (women) & NA.* & NA.* \\
\hline $\mathrm{CV}$ risk factors & 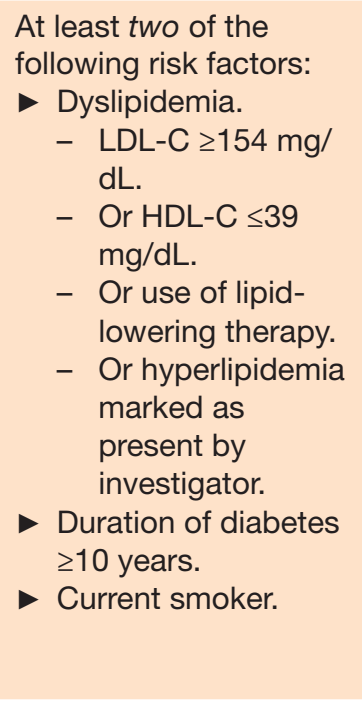 & 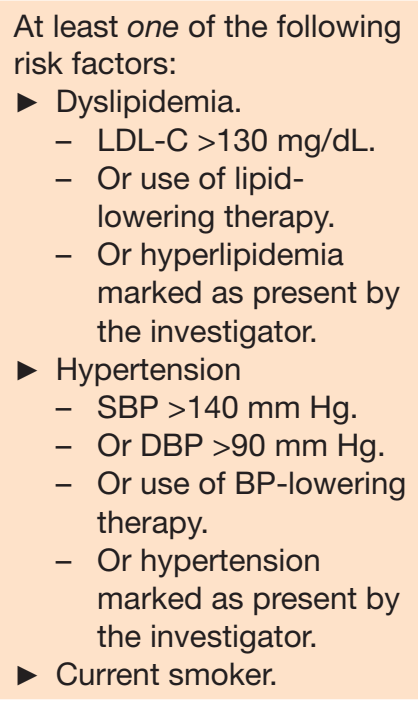 & NA.* & NA.* \\
\hline \multicolumn{5}{|c|}{ Patients with established CVD } \\
\hline Age, years & $\geq 30$ & $\geq 40$ & $\geq 18$ & $\geq 40$ \\
\hline CV history & $\begin{array}{l}\text { History of at least one } \\
\text { of the following: } \\
\text { Angina } \\
\text { CABG. } \\
\text { CAD. } \\
\text { - Ischemic stroke. } \\
\text { - HF. } \\
\text { MI. } \\
\text { PCl. }\end{array}$ & $\begin{array}{l}\text { History of at least one of the } \\
\text { following: } \\
\text { CABG } \\
\text { - CAD. } \\
\text { - Carotid stenting. } \\
\text { - Endarterectomy. } \\
\text { - Ischemic stroke. } \\
\text { - Lower extremity } \\
\text { amputation. } \\
\text { MI. } \\
\text { MAD. } \\
\text { PCl. }\end{array}$ & $\begin{array}{l}\text { History of at least one } \\
\text { of the following: } \\
\text { Angina. } \\
\text { CABG. } \\
\text { CAD. } \\
\text { - Ischemic or } \\
\text { hemorrhagic stroke. } \\
\text { Lower extremity } \\
\text { amputation. } \\
\text { MI. } \\
\text { MAD. } \\
\text { PCl. }\end{array}$ & $\begin{array}{l}\text { History of at least one } \\
\text { of the following: } \\
\text { Angina. } \\
\text { CABG. } \\
\text { CAD. } \\
\text { - Ischemic stroke. } \\
\text { MI. } \\
\text { - PAD. } \\
\text { PCI. }\end{array}$ \\
\hline
\end{tabular}

${ }^{*}$ No patients without established CVD in EMPA-REG OUTCOME and VERTIS-CV.

$\mathrm{BMI}$, body mass index; BP, blood pressure; CABG, coronary artery bypass graft; CAD, coronary artery disease; CKD, chronic kidney disease; CV, cardiovascular; CVD, cardiovascular disease; DBP, diastolic blood pressure; eGFR, estimated glomerular filtration rate; $\mathrm{HbA}_{1 \mathrm{c}}$, glycated hemoglobin; HDL-C, high-density lipoprotein cholesterol; HF, heart failure; LDL-C, low-density lipoprotein cholesterol; MI, myocardial infarction; NA, not applicable; PAD, peripheral artery disease; PCI, percutaneous coronary intervention; SBP, systolic blood pressure.

women $(56.1 \%$ vs $43.9 \%)$. The mean $\mathrm{HbA}_{1 c}$ level was $8.3 \%$ and the mean BMI was $29.1 \mathrm{~kg} / \mathrm{m}^{2}$. Overall, hypertension, hyperlipidemia, CKD, and macrovascular complications were recorded by the investigators as present in
$51.8 \%, 49.7 \%, 5.6 \%$, and $14.4 \%$ of patients, respectively. Lipid-lowering drugs and antihypertensive drugs were being used by $48.9 \%$ and $50.5 \%$ of patients, respectively. Of note, the prevalence of macrovascular complications 
Table 2 Availability of data used to assess the eligibility of patients in the DISCOVER study for CANVAS, DECLARE-TIMI 58, EMPA-REG OUTCOME, and VERTIS-CV, overall and by region

\begin{tabular}{|c|c|c|c|c|c|}
\hline & Overall & Asia-Pacific & Europe & Latin America & $\begin{array}{l}\text { Middle East and } \\
\text { Africa }\end{array}$ \\
\hline & $\mathrm{N}=15992$ & $\mathrm{n}=7517$ & $\mathrm{n}=2943$ & $n=1616$ & $n=3530$ \\
\hline Age & $15992(100.0)$ & $7517(100.0)$ & $2943(100.0)$ & $1616(100.0)$ & $3530(100.0)$ \\
\hline Sex & $15988(100.0)$ & $7517(100.0)$ & 2939 (99.9) & $1616(100.0)$ & $3530(100.0)$ \\
\hline $\mathrm{HbA}_{1 \mathrm{c}}$ & $12784(79.9)$ & $5738(73.4)$ & $2506(85.2)$ & $125(77.4)$ & $3009(85.2)$ \\
\hline BMI & 14757 (92.3) & $7084(94.2)$ & 2747 (93.3) & $1251(77.4)$ & $3126(88.6)$ \\
\hline Smoking status & $15600(97.5)$ & $7362(97.9)$ & $2843(96.6)$ & $1584(98.0)$ & $3431(97.2)$ \\
\hline Information on comedication use & $15992(100.0)$ & $7517(100.0)$ & $2943(100.0)$ & $1616(100.0)$ & $3530(100.0)$ \\
\hline \multicolumn{6}{|l|}{ Information on comorbidities ${ }^{\star}$} \\
\hline Hypertension & $15971(99.9)$ & $7517(100.0)$ & 2922 (99.3) & $1616(100.0)$ & $3530(100.0)$ \\
\hline Hyperlipidemia & 15971 (99.9) & $7517(100.0)$ & 2922 (99.3) & $1616(100.0)$ & $3530(100.0)$ \\
\hline CKD & $15971(99.9)$ & $7517(100.0)$ & 2922 (99.3) & $1616(100.0)$ & $3530(100.0)$ \\
\hline CVD† & $15947(99.7)$ & $7517(100.0)$ & 2898 (98.5) & $1616(100.0)$ & $3530(100.0)$ \\
\hline eGFR & $8782(54.9)$ & $4267(56.8)$ & $1754(59.6)$ & $732(45.3)$ & $2013(57.0)$ \\
\hline LDL-C & $8765(54.8)$ & $4226(56.2)$ & $1693(57.5)$ & $715(44.2)$ & $1871(53.0)$ \\
\hline HDL-C & $8786(54.9)$ & 4150 (55.2) & 1739 (59.1) & 792 (49.0) & 1833 (51.9) \\
\hline SBP & $15252(95.4)$ & 7299 (97.1) & 2778 (94.4) & 1539 (95.2) & 3259 (92.3) \\
\hline DBP & 15239 (95.3) & 7289 (97.0) & 2778 (94.4) & 1539 (95.2) & 3256 (92.2) \\
\hline Patients included in the analysis & $11385(71.2)$ & 5206 (69.2) & 2174 (73.9) & $1161(71.8)$ & 2624 (74.3) \\
\hline
\end{tabular}

Data are reported as $\mathrm{n}(\%)$ for patients with available data.

${ }^{*}$ Marked as present or not present by the investigator in the electronic case report form.

†Composite of coronary heart disease, cerebrovascular disease, peripheral artery disease, heart failure, and implantable cardioverter defibrillator use.

$\ddagger$ Patients with available information on age, sex, $\mathrm{HbA}_{10}$, BMI, smoking status, comedication use, and comorbidities.

$\mathrm{BMI}$, body mass index; CKD, chronic kidney disease; CVD, cardiovascular disease; DBP, diastolic blood pressure; eGFR, estimated glomerular filtration rate; $\mathrm{HbA}_{1 \mathrm{c}}$, glycated hemoglobin; $\mathrm{HDL}-\mathrm{C}$, high-density lipoprotein cholesterol; LDL-C, low-density lipoprotein cholesterol; SBP, systolic blood pressure.

varied substantially across regions $(9.8 \%-28.9 \%)$; it was highest in Europe and lowest in the Asia-Pacific region. Similarly, the proportions of patients using lipid-lowering drugs and antihypertensive drugs were higher in Europe than in other regions $(55.9 \%$ vs $45.7 \%-49.9 \%$ and $69.7 \%$ vs $44.1 \%-57.4 \%$, respectively).

Some characteristics of DISCOVER patients included in the analysis were substantially different from those of the patients enrolled in the CVOTs (online supplementary table 3). ${ }^{17} 193031$ DISCOVER patients were younger than those enrolled in the four CVOTs (mean age: 57.4 years vs 63.1-64.4 years), fewer had a history of CVD (14.4\% vs $40.6 \%-99.2 \%)$, and fewer received antihypertensive drugs $(50.5 \%$ vs $79.8 \%-94.4 \%)$. DISCOVER also included a larger proportion of women than the CVOTs (43.9\% vs $28.5 \%-37.4 \%)$. Of note, DISCOVER patients were from more diverse geographic origins than patients in the CVOTs; the majority of DISCOVER patients were from the Asia-Pacific region (45.7\%), and the Middle East and Africa (23.0\%), whereas the CVOTs mainly enrolled patients from Europe $(20.0 \%-44.5 \%)$ and North America $(24.0 \%-41.0 \%)$. Some countries from the Middle East and Africa included in DISCOVER (Algeria,
Bahrain, Egypt, Jordan, Kuwait, Lebanon, Oman, Saudi Arabia, Tunisia, and the United Arab Emirates) were not represented in any of the four CVOTs.

\section{Eligibility of DISCOVER patients for CVOTs}

The proportions of DISCOVER patients eligible for each CVOT using the criteria in table 1 are shown in figure 1, overall and by region. Overall, DECLARE-TIMI 58 was the most inclusive of the four trials, with $40.5 \%$ (4611/11 385) of DISCOVER patients being eligible. Of these eligible patients, 20.3\% (938/4611) had established CVD and 79.7\% (3673/4611) had CV risk factors but no established CVD. CANVAS was the second most inclusive CVOT with 19.9\% (2260/11 385) of DISCOVER patients being eligible. Of these eligible patients, $37.5 \%$ $(848 / 2260)$ had established CVD and 62.5\% (1412/2260) had CV risk factors but no established CVD. EMPA-REG OUTCOME and VERTIS-CV only included patients with established CVD and eligibility of DISCOVER patients was substantially lower (7.1\% [803/11 385] and 7.2\% [815/11 385], respectively) than for the other two trials.

Results were consistent across all studied regions, with DECLARE-TIMI 58 being the most inclusive, followed 
Table 3 Baseline characteristics of DISCOVER patients included in the analysis

\begin{tabular}{|c|c|c|c|c|c|}
\hline & $\begin{array}{l}\text { Total } \\
\mathrm{N}=11385\end{array}$ & $\begin{array}{l}\text { Asia-Pacific } \\
\mathrm{n}=5206\end{array}$ & Europe $n=2174$ & $\begin{array}{l}\text { Latin America } \\
\mathrm{n}=1161\end{array}$ & $\begin{array}{l}\text { Middle East and } \\
\text { Africa } n=2624\end{array}$ \\
\hline Men & $6387(56.1)$ & 3037 (58.3) & 1212 (55.7) & $538(46.3)$ & 1459 (55.6) \\
\hline \multicolumn{6}{|l|}{$\begin{array}{l}\text { Self-reported } \\
\text { ethnicity }\end{array}$} \\
\hline Caucasian & 3004 (27.5) & $122(2.3)$ & 1839 (94.5) & $390(33.7)$ & $644(24.6)$ \\
\hline Black & $122(1.1)$ & $1(0.0)$ & $7(0.4)$ & $58(5.0)$ & $54(2.1)$ \\
\hline Asian & 5269 (48.1) & 5069 (97.4) & $15(0.8)$ & $7(0.6)$ & $175(6.7)$ \\
\hline Hispanic & $612(5.6)$ & $1(0.0)$ & $7(0.4)$ & $603(52.1)$ & $1(0.0)$ \\
\hline Arabic & 1734 (15.8) & $2(0.0)$ & $7(0.4)$ & $2(0.2)$ & $1722(65.8)$ \\
\hline Mixed & $100(0.9)$ & $1(0.0)$ & $3(0.2)$ & $89(7.7)$ & $7(0.3)$ \\
\hline Other & $103(0.9)$ & $9(0.2)$ & 68 (3.5) & $9(0.8)$ & $16(0.6)$ \\
\hline Missing & 442 & 1 & 228 & 3 & 5 \\
\hline $\begin{array}{l}\text { Age, mean }(S D) \text {, } \\
\text { years }\end{array}$ & $57.4(12.1)$ & $56.5(12.4)$ & $63.1(10.6)$ & $58.5(11.4)$ & $54.1(10.8)$ \\
\hline $\begin{array}{l}\mathrm{HbA}_{1 \mathrm{c}} \text {, mean (SD), } \\
\%\end{array}$ & $8.3(1.7)$ & $8.3(1.7)$ & $8.0(1.5)$ & $8.5(1.9)$ & $8.6(1.6)$ \\
\hline $\begin{array}{l}\text { BMI, mean (SD), } \\
\mathrm{kg} / \mathrm{m}^{2}\end{array}$ & $29.1(5.9)$ & $26.7(4.8)$ & $31.9(6.1)$ & $30.4(5.5)$ & $31.0(5.8)$ \\
\hline $\begin{array}{l}\text { Time since T2D } \\
\text { diagnosis, mean } \\
\text { (SD), years }\end{array}$ & $5.6(5.2)$ & $5.0(5.0)$ & $6.5(5.3)$ & $6.5(6.1)$ & $6.0(5.2)$ \\
\hline \multicolumn{6}{|l|}{ Tobacco smoking } \\
\hline Non-smoker & 7596 (66.7) & $3548(68.1)$ & 1281 (58.9) & $750(64.6)$ & 1878 (71.6) \\
\hline Ex-smoker & 1990 (17.5) & $808(15.5)$ & $515(23.7)$ & 305 (26.3) & $329(12.5)$ \\
\hline Current smoker & 1799 (15.8) & $850(16.3)$ & $378(17.4)$ & $106(9.1)$ & $417(15.9)$ \\
\hline \multicolumn{6}{|l|}{ Comorbidities $^{*}$} \\
\hline Hypertension & 5899 (51.8) & 2406 (46.2) & 1569 (72.2) & $670(57.7)$ & 1103 (42.0) \\
\hline Hyperlipidemia & 5658 (49.7) & 2549 (49.0) & 1344 (61.8) & $576(49.6)$ & 1032 (39.3) \\
\hline CKD & $634(5.6)$ & $326(6.3)$ & $186(8.6)$ & $48(4.1)$ & $53(2.0)$ \\
\hline $\begin{array}{l}\text { Macrovascular } \\
\text { complication(s)† }\end{array}$ & $1634(14.4)$ & $512(9.8)$ & $628(28.9)$ & $174(15.0)$ & $289(11.0)$ \\
\hline \multicolumn{6}{|l|}{$\begin{array}{l}\text { Use of } \\
\text { comedication }\end{array}$} \\
\hline $\begin{array}{l}\text { Lipid-lowering } \\
\text { drugs }\end{array}$ & 5568 (48.9) & 2459 (47.2) & 1215 (55.9) & $579(49.9)$ & $1200(45.7)$ \\
\hline $\begin{array}{l}\text { Antihypertensive } \\
\text { drugs }\end{array}$ & 5755 (50.5) & $2297(44.1)$ & 1515 (69.7) & $666(57.4)$ & $1156(44.1)$ \\
\hline
\end{tabular}

Data are reported as $\mathrm{n}(\%)$ unless otherwise stated. The numbers of patients with missing data are reported for relevant variables; data were available for all patients for all other variables in the table. Percentages were calculated for all patients with data.

*Marked as present by the investigator in the electronic case report form.

†Composite of coronary heart disease, cerebrovascular disease, peripheral artery disease, heart failure, and implantable cardioverter defibrillator use.

$\mathrm{BMI}$, body mass index; CKD, chronic kidney disease; $\mathrm{HbA}_{1 \mathrm{c}}$, glycated hemoglobin; T2D, type 2 diabetes.

by CANVAS, VERTIS-CV, and EMPA-REG OUTCOME in all regions. The proportions of patients eligible for each CVOT were highest in Europe and lowest in the Asia-Pacific region. Findings from the sensitivity analysis were also consistent with the overall results. However, the proportions of eligible patients for the four CVOTs were slightly higher in countries that used a mixed approach to data collection (data extraction from existing databases and abbreviated electronic case report form) than in the other countries (online supplementary figure 1 ). This is attributable to the fact that most of the DISCOVER countries that used existing databases are European countries, in which the prevalence of macrovascular complications was higher than 

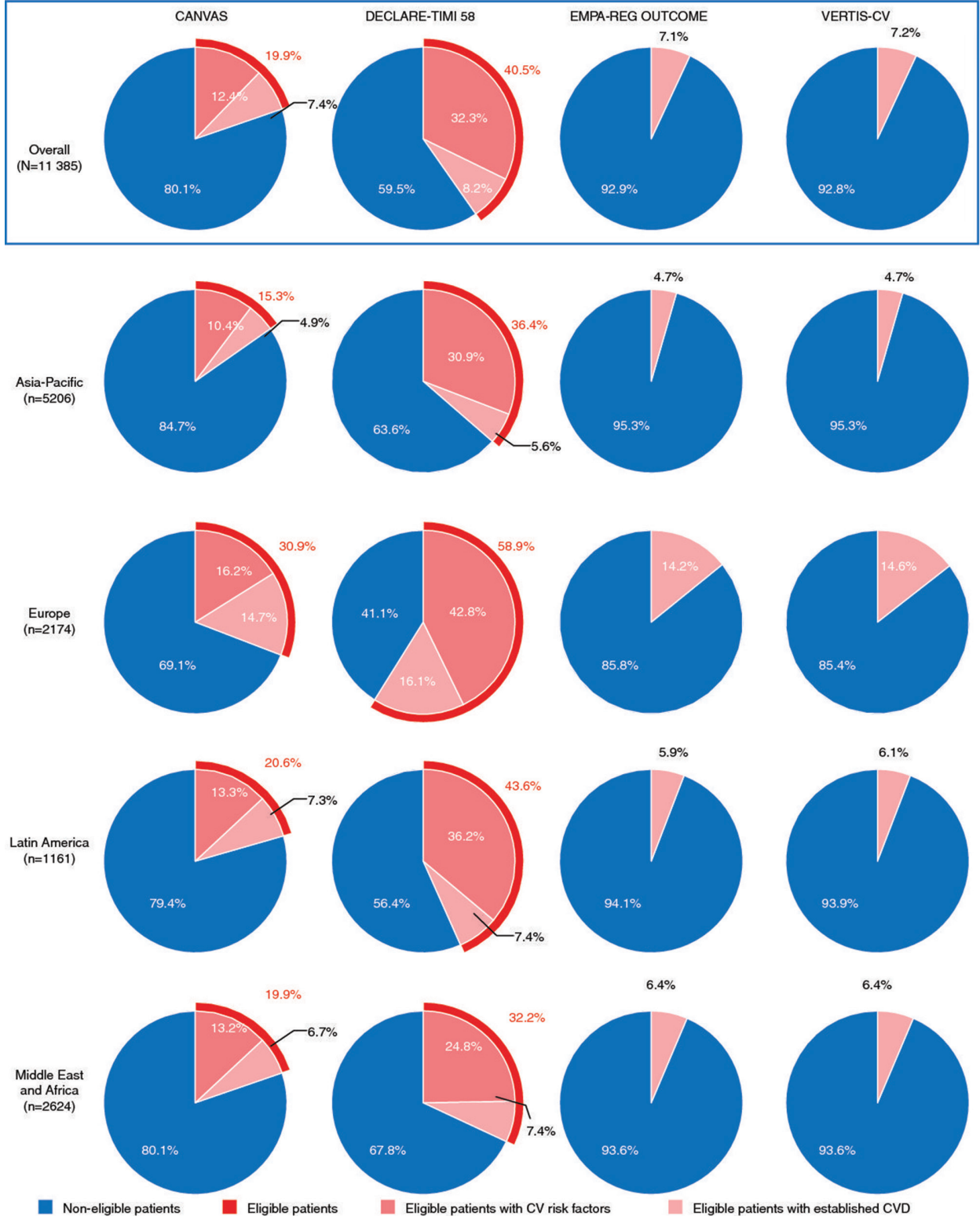

$6.4 \%$

$6.4 \%$
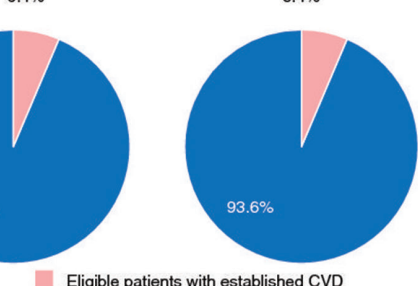

Figure 1 Estimated proportions of DISCOVER patients who would have been eligible for CANVAS, DECLARE-TIMI 58, EMPAREG OUTCOME, and VERTIS-CV. CV, cardiovascular, CVD, cardiovascular disease.

in countries from other regions, regardless of the data collection method. ${ }^{32}$

Overall, $54.6 \%$ of DISCOVER patients were not eligible for any of the four CVOTs (across-region range: 35.3\%$62.0 \%$; data not shown), and only $6.2 \%$ were eligible for all four CVOTs (across-region range: $4.1 \%-12.4 \%$; data not shown).

\section{DISCUSSION}

In this cross-sectional analysis, the eligibility of DISCOVER patients varied greatly across the four SGLT-2 inhibitor CVOTs. In line with the results of the previous assessment of the NHANES population, ${ }^{24}$ DECLARE-TIMI 58 was the most inclusive trial, with an estimated $40.5 \%$ of DISCOVER patients eligible, followed by CANVAS, with an estimated $19.9 \%$ of DISCOVER patients eligible. Relatively low estimates for the proportions of eligible
DISCOVER patients for EMPA-REG OUTCOME (7.1\%) and VERTIS-CV $(7.2 \%)$ are largely explained by the fact that these trials only included patients with established CVD.

It is therefore unknown whether the results from EMPA-REG OUTCOME and VERTIS-CV are applicable to most patients encountered in routine clinical practice. Indeed, the observational CVD-REAL study suggests that, as a class, SGLT-2 inhibitors provide CV benefits in patients with and without established CVD, ${ }^{33-35}$ which indicates that CVOTs should not be conducted exclusively in patients with CVD and need to be complemented by other data. This is also illustrated by the observation that more than half of the DISCOVER patients were not eligible for any of the four CVOTs.

Like DECLARE-TIMI 58, CANVAS included both patients with established CVD and patients with CV 
risk factors but no established CVD. The difference in eligibility of DISCOVER patients for these two trials is a result of more stringent entry criteria for CANVAS than for DECLARE-TIMI 58. For example, the $\mathrm{HbA}_{1 \mathrm{c}}$ range for inclusion was narrower in CANVAS than in DECLARE-TIMI 58 (7.0\%-10.5\% vs $6.5 \%-12.0 \%)$. In addition, patients had to have at least two CV risk factors to be eligible for CANVAS, but only one to be eligible for DECLARE-TIMI 58. Conversely, patients with an eGFR between 30 and $60 \mathrm{~mL} / \mathrm{min} / 1.73 \mathrm{~m}^{2}$ could be included in CANVAS, but not in DECLARE-TIMI 58.

Results were consistent across all studied regions and DECLARE-TIMI 58 remained the most inclusive GVOT. However, the proportion of DISCOVER patients eligible for each CVOT varied substantially across regions, which is mainly explained by the differing prevalence of macrovascular complications (table 3). The higher the prevalence of macrovascular complications, the higher the proportion of patients eligible for CVOTs. The results from this analysis of DISCOVER patients were also consistent with the previous analysis based on the NHANES population, which showed that DECLARETIMI 58 was the most inclusive CVOT with $39.8 \%$ of patients being eligible. ${ }^{24}$ However, the proportions of patients from the DCR and the DISCOVER populations who were eligible for EMPA-REG OUTCOME were substantially different $(26.2 \%$ and $7.1 \%$, respectively). ${ }^{25}$ This is explained by the fact that most sites providing data to the DCR at the time of the analysis were cardiology practices, which are likely to manage patients with established CVD. Indeed, $52.9 \%$ of DCR patients for whom $\mathrm{HbA}_{1 \mathrm{c}}$ data were available had established CVD. In contrast, $14.4 \%$ of the DISCOVER patients included in the present analysis had a recorded history of macrovascular complications. Results from the DISCOVER, NHANES, and DCR populations should be compared with caution because, in addition to the population differences mentioned above, the analyses used different criteria to assess patients' eligibility for CVOTs. Of note, the study on the DCR population only used key criteria to assess eligibility for EMPA-REG OUTCOME ( 218 years of age, $\mathrm{HbA}_{1 \mathrm{c}}$ level between $7.0 \%$ and $10.0 \%$, and established CVD). ${ }^{25}$ In contrast, the study on the NHANES population and the present assessment of the DISCOVER population used a very similar approach based on more detailed inclusion criteria. However, the presence of comorbidities was assessed in different ways. In the DISCOVER study, the assessment of comorbidities relied on the investigators' judgment, whereas in the NHANES study it relied on asking the patients simple questions about their medical history. ${ }^{24}$

\section{Strengths and limitations}

The DISCOVER study program includes a large and diverse sample of patients with T2D from 38 countries, thus providing results that complement those obtained from US and UK databases. Of note, DISCOVER includes 10 countries in the Middle East and Africa, which were not represented in any of the CVOTs. The comprehensive DISCOVER electronic case report form used for data collection provided the necessary information to assess eligibility for a large proportion of patients and allowed comparisons across regions. ${ }^{28}$ However, this analysis only used key inclusion and exclusion criteria from the four CVOTs, which may have led to an overestimation or underestimation of the numbers of eligible patients. Similarly, DISCOVER variables were matched as closely as possible to CVOT enrollment criteria but were not always identical, which may decrease the accuracy of the reported estimates.

In line with the observational nature of DISCOVER, data collection reflects routine clinical practice: the protocol did not mandate any laboratory tests or adjudication of events. As such, some DISCOVER patients could not be included in the analysis because key data were not reported. For example, $\mathrm{HbA}_{1 \mathrm{c}}$ levels were not recorded for $20.1 \%$ of the DISCOVER patients because alternative measures of blood glucose levels were routinely used instead at some sites; $55.2 \%$ of patients without a recorded $\mathrm{HbA}_{1 \mathrm{c}}$ level had a measurement of fasting plasma glucose (data not shown). For some patients, comorbidities were marked as present by the physician without recorded laboratory test result evidence (eg, hyperlipidemia marked as present without recorded values for LDL-C and/or HDL-C).

It should also be noted that the DISCOVER population is not representative of the general population of patients with T2D because it only included patients who were initiating a second-line glucose-lowering therapy. Although it is inherently difficult to achieve a representative sample in a large, international, observational study such as DISCOVER, efforts made at the start of the study to reach this goal resulted in the inclusion of a heterogeneous patient population from clinical settings with diverse characteristics in most participating countries; ${ }^{28} 29$ overall, sex and ethnicity distributions were in line with those of the general population of patients with diabetes. ${ }^{29}$ DISCOVER patients also constitute the best-characterized, contemporary population of patients with T2D in many participating countries, which allows comparisons of findings between different regions.

\section{CONCLUSION}

In a large, global population of patients with T2D initiating a second-line glucose-lowering therapy covering countries and regions not previously studied, DECLARETIMI 58 was the most inclusive of all four ongoing or completed SGLT-2 inhibitor CVOTs, globally and in the four predefined regions. These results are in line with and complement previous findings from US and UK databases. The high proportion of DISCOVER patients not eligible for any of the four CVOTs studied here also suggests that further research is required to assess 
the CV benefits of SGLT-2 inhibitors in a wider population, including patients at lower CV risk. Indeed, realworld evidence studies such as CVD-REAL suggest that patients with a lower CV risk could benefit from treatment with SGLT-2 inhibitors. The different proportions of DISCOVER patients eligible for CVOTs across regions also highlight the differences in healthcare between countries, and therefore the need to include less frequently studied countries in future research, such as those in the Middle East and Africa.

\author{
Author affiliations \\ ${ }^{1}$ Oxford PharmaGenesis, 0xford, UK \\ ${ }^{2}$ AstraZeneca, Cambridge, UK \\ ${ }^{3}$ Institute of Environmental Medicine, Karolinska Institute, Stockholm, Sweden \\ ${ }^{4}$ Peking University People's Hospital, Beijing, China \\ ${ }^{5}$ Diabetes Research Centre, University of Leicester, Leicester, UK \\ ${ }^{6}$ AstraZeneca, Madrid, Spain \\ ${ }^{7}$ Saint Luke's Mid America Heart Institute, Kansas City, Missouri, USA \\ ${ }^{8}$ AstraZeneca, Gaithersburg, Maryland, USA \\ ${ }^{9}$ AstraZeneca, Luton, UK
}

Acknowledgements The authors would like to thank all DISCOVER, CANVAS, DECLARE-TIMI 58, EMPA-REG OUTCOME, and VERTIS-CV patients and investigators. Editorial support was provided by Oxford PharmaGenesis, Oxford, UK and was funded by AstraZeneca.

Contributors The proposal for the analysis was developed by SP and FS and reviewed by all authors. The general content of the manuscript was agreed upon by all authors. The statistical analysis was conducted by FT. The first draft of the manuscript was developed by SP and critically reviewed by all authors. All authors approved the final version of the manuscript before its submission. An AstraZeneca team reviewed the manuscript during its development and could make suggestions. However, the final content was determined by the authors. SP is the guarantor of this work.

Funding The DISCOVER and DECLARE-TIMI 58 studies are funded by AstraZeneca. The CANVAS study is funded by Janssen. The EMPA-REG OUTCOME study is funded by Boehringer Ingelheim and Eli Lilly. The VERTIS-CV study is funded by Merck Sharp \& Dohme and Pfizer.

Competing interests SP is an employee of Oxford PharmaGenesis. PF, JM, EW, and FS are employees of AstraZeneca. NH is a former employee of AstraZeneca. LJ has received honoraria from AstraZeneca, Bayer, Boehringer Ingelheim, BristolMyers Squibb, Eli Lilly, Merck Sharp \& Dohme, Novartis, Novo Nordisk, Roche, Sanofi, and Takeda, and research support from AstraZeneca, Bristol-Myers Squibb, Eli Lilly, Merck Sharp \& Dohme, Novartis, Roche, and Sanofi. KK has received honoraria from AstraZeneca, Boehringer Ingelheim, Eli Lilly, Janssen, Merck Sharp \& Dohme, Novartis, Novo Nordisk, Roche, and Sanofi, and research support from AstraZeneca, Boehringer Ingelheim, Eli Lilly, Janssen, Merck Sharp \& Dohme, Novartis, Novo Nordisk, Roche, and Sanofi, and also acknowledges support from the National Institute for Health Research Collaboration for Leadership in Applied Health Research and Care - East Midlands (NIHR CLAHRC - EM) and the National Institute for Health Research (NIHR) Leicester Biomedical Research Centre. FT is an employee of the Mid America Heart Institute, which received institutional funding from AstraZeneca.

\section{Patient consent for publication Not required.}

Ethics approval The DISCOVER study protocol was approved by the appropriate clinical research ethics committees in each participating country and by the relevant institutional review boards at each site. The protocol complies with the Declaration of Helsinki, the International Conference on Harmonization on Good Clinical Practice, and the local regulations for clinical research.

Provenance and peer review Not commissioned; externally peer reviewed.

Data sharing statement DISCOVER data underlying the findings described in this manuscript may be obtained in accordance with AstraZeneca's data sharing policy described at https://astrazenecagrouptrials. pharmacm.com/ST/Submission/ Disclosure
Open access This is an open access article distributed in accordance with the Creative Commons Attribution Non Commercial (CC BY-NC 4.0) license, which permits others to distribute, remix, adapt, build upon this work non-commercially, and license their derivative works on different terms, provided the original work is properly cited, appropriate credit is given, any changes made indicated, and the use is non-commercial. See: http://creativecommons.org/licenses/by-nc/4.0/.

\section{REFERENCES}

1. American Diabetes Association. Standards of medical care in diabetes 2019. In: Diabetes care. 2017:40: S1-129.

2. Fowler MJ. Microvascular and macrovascular complications of diabetes. Clinical Diabetes 2008;26:77-82.

3. Patel A, MacMahon S, Chalmers J, et al. Intensive blood glucose control and vascular outcomes in patients with type 2 diabetes. $N$ Engl J Med 2008;358:2560-72.

4. Holman RR, Paul SK, Bethel MA, et al. 10-year follow-up of intensive glucose control in type 2 diabetes. N Engl J Med 2008;359:1577-89.

5. King P, Peacock I, Donnelly R. The UK prospective Diabetes Study (UKPDS): clinical and therapeutic implications for type 2 diabetes. $\mathrm{Br}$ $J$ Clin Pharmacol 1999;48:643-8.

6. Ohkubo Y, Kishikawa H, Araki E, et al. Intensive insulin therapy prevents the progression of diabetic microvascular complications in Japanese patients with non-insulin-dependent diabetes mellitus: a randomized prospective 6-year study. Diabetes Res Clin Pract 1995:28:103-17.

7. Stratton IM, Adler Al, Neil HA, et al. Association of glycaemia with macrovascular and microvascular complications of type 2 diabetes (UKPDS 35): prospective observational study. BMJ 2000;321:405-12.

8. Kelly TN, Bazzano LA, Fonseca VA, et al. Systematic review: glucose control and cardiovascular disease in type 2 diabetes. Ann Intern Med 2009;151:394-403.

9. Hemmingsen B, Lund SS, Gluud C, et al. Intensive glycaemic control for patients with type 2 diabetes: systematic review with metaanalysis and trial sequential analysis of randomised clinical trials. BMJ 2011;343:d6898

10. Gerstein HC, Miller ME, et al. Effects of intensive glucose lowering in type 2 diabetes. N Engl J Med 2008;358:2545-59.

11. Hiatt WR, Kaul S, Smith RJ. The cardiovascular safety of diabetes drugs--insights from the rosiglitazone experience. N Engl J Med 2013;369:1285-7.

12. Lincoff AM, Wolski K, Nicholls SJ, et al. Pioglitazone and risk of cardiovascular events in patients with type 2 diabetes mellitus: a meta-analysis of randomized trials. JAMA 2007:298:1180-8.

13. Sardar P, Udell JA, Chatterjee S, et al. Effect of intensive versus standard blood glucose control in patients with type 2 diabetes mellitus in different regions of the world: systematic review and meta-analysis of randomized controlled trials. J Am Heart Assoc 2015;4:e001577.

14. Food and Drug Administration. Guidance for industry diabetes mellitus - evaluating cardiovascular risk in new antidiabetic therapies to treat type 2 diabetes, 2008. Available: https://www.fda.gov/ downloads/Drugs/./Guidances/ucm071627 [Accessed 8 Oct 2018].

15. Neal B, Perkovic V, Matthews DR, et al. Rationale, design and baseline characteristics of the CANagliflozin cardioVascular Assessment Study-Renal (CANVAS-R): a randomized, placebocontrolled trial. Diabetes Obes Metab 2017;19:387-93.

16. Neal B, Perkovic V, de Zeeuw D, et al. Rationale, design, and baseline characteristics of the CANagliflozin cardioVascular Assessment Study (CANVAS)--a randomized placebo-controlled trial. Am Heart J 2013;166:217-23.

17. Neal B, Perkovic V, Mahaffey KW, et al. Optimizing the analysis strategy for the CANVAS Program: a prespecified plan for the integrated analyses of the CANVAS and CANVAS-R trials. Diabetes Obes Metab 2017;19:926-35.

18. Wiviott SD, Raz I, Bonaca MP, et al. The design and rationale for the Dapagliflozin Effect on Cardiovascular Events (DECLARE)-TIMI 58 Trial. Am Heart J 2018;200:83-9.

19. Zinman B, Inzucchi SE, Lachin JM, et al. Rationale, design, and baseline characteristics of a randomized, placebo-controlled cardiovascular outcome trial of empagliflozin (EMPA-REG OUTCOMETM). Cardiovasc Diabetol 2014;13:102

20. ClinicalTrials.gov. Cardiovascular outcomes following ertugliflozin treatment in type 2 diabetes mellitus participants with vascular disease, the VERTIS CV study (MK-8835-004), 2013. Available: https://clinicaltrials.gov/ct2/show/NCT01986881 [Accessed 8 Oct 2018].

21. Zinman B, Wanner C, Lachin JM, et al. Empagliflozin, cardiovascular outcomes, and mortality in type 2 diabetes. N Engl $\mathrm{J} \mathrm{Med}$ 2015;373:2117-28 
22. Mahaffey KW, Neal B, Perkovic V, et al. Canagliflozin for primary and secondary prevention of cardiovascular events: results from the CANVAS Program (canagliflozin cardiovascular assessment study). Circulation 2018;137:323-34.

23. AstraZeneca. Farxiga achieved a positive result in the phase III DECLARE-TIMI 58 trial, a large cardiovascular outcomes trial in 17,000 patients with type-2 diabetes, 2018. Available: https:// www.astrazeneca.com/media-centre/press-releases/2018/farxigaachieved-a-positive-result-in-the-phase-iii-declare-timi-58-trial-alarge-cardiovascular-outcomes-trial-in-17000-patients-with-type-2diabetes-24092018.html [Accessed 8 Oct 2018].

24. Wittbrodt ET, Eudicone JM, Bell KF, et al. Eligibility varies among the 4 sodium-glucose cotransporter-2 inhibitor cardiovascular outcomes trials: implications for the general type 2 diabetes US population. Am J Manag Care 2018;24(8 Suppl):S138-45.

25. Arnold SV, Inzucchi SE, Tang F, et al. Real-world use and modeled impact of glucose-lowering therapies evaluated in recent cardiovascular outcomes trials: an NCDR Research to Practice project. Eur J Prev Cardiol 2017;24:1637-45.

26. McGovern A, Feher M, Munro N, et al. Sodium-glucose cotransporter 2 (SGLT2) inhibitor: comparing trial data and real-world use. Diabetes Ther 2017;8:365-76.

27. International Diabetes Federation. IDF Diabetes Atlas. 8th edn. International Diabetes Federation, 2017.

28. Ji L, Bonnet F, Charbonnel B, et al. Towards an improved global understanding of treatment and outcomes in people with type 2 diabetes: rationale and methods of the DISCOVER observational study program. J Diabetes Complications 2017;31:1188-96.
29. Rathmann W, Medina J, Kosiborod M, et al. The DISCOVER study: diversity of sites, physicians, and patients. Pharmacoepidemiol Drug Saf 2018;27:228.

30. Cannon CP, McGuire D, Pratley R, et al. Design and baseline characteristics of the evaluation of ERTUGLIFOZIN efficacy and safety cardiovascular outcomes trial (VERTIS-CV). J Am Coll Cardiol 2018;71:1825.

31. Raz I, Mosenzon O, Bonaca MP, et al. DECLARE-TIMI 58: participants' baseline characteristics. Diabetes Obes Metab 2018;20:1102-10.

32. Kosiborod M, Gomes MB, Nicolucci A, et al. Vascular complications in patients with type 2 diabetes: prevalence and associated factors in 38 countries (the DISCOVER study program). Cardiovasc Diabetol 2018;17:150.

33. Kosiborod M, Lam CSP, Kohsaka S, et al. Cardiovascular events associated with SGLT-2 inhibitors versus other glucose-lowering drugs: the CVD-REAL 2 study. J Am Coll Cardiol 2018;71:2628-39.

34. Kosiborod M, Cavender MA, Fu AZ, et al. Lower risk of heart failure and death in patients initiated on sodium-glucose cotransporter-2 inhibitors versus other glucose-lowering drugs: the CVD-REAL study (comparative effectiveness of cardiovascular outcomes in new users of sodium-glucose cotransporter-2 inhibitors). Circulation 2017:136:249-59.

35. Kosiborod M, Birkeland KI, Cavender MA, et al. Rates of myocardial infarction and stroke in patients initiating treatment with SGLT2inhibitors versus other glucose-lowering agents in real-world clinical practice: results from the CVD-REAL study. Diabetes Obes Metab 2018;20:1983-7. 